\title{
ФИЗИЧЕСКОЕ МОДЕЛИРОВАНИЕ ДЕЙСТВИЯ НИЗКОИНТЕНСИВНОГО ИК-ИЗЛУЧЕНИЯ НА БИОТКАНИ
}

\begin{abstract}
В.А. Степанов, О.В. Розова
ВЛАДИМИР АЛЕКСАНДРОВИЧ СТЕПАНОВ - д.ф.-м.н., профессор Обнинского института атомной энергетики Научно-исследовательского ядерного университета МИФИ, ведущий научный сотрудник ФГБУН Межведомственного иентра аналитических исследований в области физики, химии и биологии при Президиуме PAH. E-mail: stepanov@iate.obninsk.ru.
\end{abstract}

ОЛЬГА ВЛАДИМИРОВНА РОЗОВА - студентка Обнинского института атомной энергетики Научноисследовательского ядерного университета МИФИ. E-mail: ovrozova@mail.ru.

249030, Калужская обл., г. Обнинск, Студгородок, д. 1. Обнинский институт атомной энергетики НИЯУ МИФИ.

117997, г. Москва, ул. Профсоюзная, д. 65, стр. 6. ФГБУН Межведомственный центр аналитических исследований в области физики, химии и биологии при Президиуме РАН.

Проведено сравнение воздействия импульсного и непрерывного инзкоинтенсивного инфракрасного излучения на морфологию клеточных культур HEK-293. Доказано влияние импульсного ИК-облучения, заключающееся в увеличении оптического контраста грании клеток. Обсуждается механизм деформаиий клеточных мембран при нерезонансном рассеянии света.

Ключевые слова: лазерная терапия, ИК-излучение, клеточные культуры.

\section{PHYSICAL MODELING OF INFLUENCE LOW-INTENSITY IR RADIATION ON BIOLOGICAL TISSUES}

\author{
V.A. Stepanov ${ }^{1,2}$, O.V. Rozova ${ }^{1}$ \\ ${ }^{1} 1$ Studgorodok st., Kaluga rg., Obninsk, 249040, Russia. National research nuclear university (NRNU) MEPh. \\ ${ }^{2} 65$ Profsoyuznaya Street, Moscow, 117997, Russia. Interdepartment Center of Analytical Research in Physics, \\ Chemistry, and Biology, Presidium of Russian Academy of Sciences.
}

The effect of pulsed and continuous non-intense infrared radiation on the morphology of HEK-293 cell cultures is compared. The effect of pulsed IR irradiation, which consists in increasing the optical contrast of cell boundaries, is proved. The mechanism of deformation of cell membranes during non-resonant light scattering is discussed.

Key words: laser therapy, infrared radiation, cell cultures. 


\section{Введение}

В зависимости от характера инициируемых эффектов различают три вида взаимодействия лазерного излучения с биологическими тканями [13]. Во-первых, термодеструктивное воздействие, при котором в результате лазерного облучения высокой интенсивности в спектральной области поглощения излучения происходит деструкция биологических тканей. Такой вид воздействия применяют в лазерной хирургии. Во-вторых, фотофизическое и фотохимическое воздействие, связанное с селективным поглощением излучения различными компонентами биотканей, например, отдельными макро-молекулами и клетками. На избирательной деструкции при облучении основана фотодинамическая терапия. Наконец, нерезонансное воздействие света приводит к стимулированию микроциркуляторных процессов в межклеточных областях и в сосудистом русле. Такой вид воздействия используют в лазерной терапии.

Лечение с использованием низкоинтенсивного лазерного излучения (НИЛИ) является эффективным физиотерапевтическим методом. В соответствии с открытым в 90-х годах нерезонансным механизмом влияния светового воздействия на микроциркуляцию в биотканях $[4,5]$ при воздействии НИЛИ в результате процессов рассеяния в биологических тканях возникают неоднородности температурного поля. Это приводит к деформациям клеточных мембран и изменению их электропотенциала. Деформации биологических мембран существенно влияют на обменные процессы в клетках и между клетками. Например, периодические стимулированные деформации клеток стенок сосудов воспаленных участков биоткани облегчают циркуляцию жидких компонент.

Поначалу для терапии НИЛИ использовали красные $\mathrm{He}-\mathrm{Ne}$ - лазеры с длиной волны 0,63 мкм. Излучение вводили в кровяные сосуды с помощью катетеров [6]. Но свет Не-Ne - лазера с высокой когерентностью приводит к высокой интенсивности в отдельных спеклах, к деструкции части молекул и даже клеток и, как следствие, к осложнениям в лечении. Поэтому лечение внутренних органов стали осуществлять непосредственно через кожу облучением GaAs - лазера с длиной волны 0,89 мкм, попадающего в окно прозрачности биотканей $[5,7,8]$. Глубина проникновения излучения составляет 4-7 см. Большую эффективность действия излучения с длиной волны 0,89 мкм по сравнению с 0,63 мкм отмечают и в современных исследованиях (например, $[9,10])$. Как и 30 лет назад в исследованиях продолжают наблюдать сильную зависимость био-эффективности импульсно- го воздействия от частоты посылок лазерных импульсов [11]. Независимость биостимуляции от поляризации и когерентности была обнаружена еще в 80-х годах прошлого века $[12,13]$, так что, для лечения НИЛИ оказались важны выбор диапазона длин волн, интенсивность излучения и частота импульсного воздействия.

Если в условиях лазерной хирургии или фотодинамической терапии механизмы действия лазерного излучения и физико-химические процессы в биотканях подробно изучены, то применительно к ИК-лазерной низкоинтенсивной терапии имеется только теоретическая модель, некоторые результаты клинических испытаний на животных и людях. Непосредственные исследования по влиянию параметров ИК-облучения на клеточные структуры, которые позволили бы получить экспериментальное обоснование условий успешной терапии отсутствуют. В данной работе предпринята попытка физического моделирования инициируемых процессов в биотканях на примере изучения отклика клеточных структур на низкоинтенсивное ИКизлучение, причем для начала в сравнении непрерывного и импульсного воздействия.

\section{Теоретическое описание}

В области прозрачности в результате многократного рассеяния ИК-излучения в биотканях возникает неоднородное температурное поле. В работах $[4,5]$ было показано, что в реальных условиях лазерной терапии (например, $\mathrm{He}-\mathrm{Ne}-, \mathrm{GaAs}-$ лазерами) при средней мощности до нескольких мкВт возникает перепад температуры в микрообластях порядка $10^{-2}-10^{-1} \mathrm{~K}$, и деформация клеточных мембран составляет до $10^{-2}-10^{-1}$, а изменение их электропотенциала происходит на $10^{-1}-10^{1} \mathrm{MB}$. Было показано, что если эффективность лазерной терапии оценивать по амплитуде деформации и изменений электропотенциала клеточных мембран, то такая эффективность оказывается выше в случае использования импульсного воздействия, и ее зависимость от частоты посылок лазерных импульсов имеет максимум, определяемый из соотношения:

$$
\omega_{\max }=\frac{10^{4}}{d(\mathcal{M} \kappa \mathcal{M})\left(d^{4}\left(\mathcal{M} \kappa \mathcal{M}^{4}\right)+10^{2}\right)^{1 / 4}}(\Gamma ц),
$$

где $d$ - характерный размер структурных компонент - оптических неоднородностей в биоткани. Частоту импульсного лазерного воздействия необходимо подбирать в зависимости от морфологии биоткани. Варьируя частоту посылки лазерных импульсов, можно оказывать воздействие селек- 
тивно на различные структуры биотканей. Этот вывод был подтвержден экспериментальными исследованиями изменения морфологии различных тканей после лазерного воздействия, а также опытом лечения хронических неспецифических воспалительных заболеваний внутренних органов $[5,7$, 8]. Например, экспериментальные исследования микроциркуляции крови в капиллярах тканей крыс при воздействии НИЛИ показали, что после лазерного облучения усиливается капиллярный кровоток и увеличивается площадь капиллярного русла. В соответствии с (1) с учетом размеров капилляров сердечной мышцы человека $\mathrm{d} \sim 10$ мкм получена оценка частоты $\omega_{\max }=10^{2}$ Гц, на которой проводили лечение ишемической болезни сердца. Показано, что у 98 \% обследованных больных произошло улучшение сократительной функции миокарда.

Формула (1) была получена путем совместного решения следующих уравнений. Нарушение равенства концентраций или температур по обе стороны клеточной мембраны приводит к возникновению осмотического давления на мембрану:

$$
\Delta p=n R T\left(\frac{\Delta T}{T}+\frac{\Delta n}{n}\right)
$$

В том случае, когда область изменения температуры и концентрации вблизи мембраны ограничена размером $d$, давление приводит к поперечному смещению мембраны на $x \cong \Delta p \frac{d^{2}}{h E}$, где $h$ - толщина мембраны ( 10 нм), $E$ - модуль Юнга сдвиговой деформации двойного липидного слоя ( $10^{5}$ Па), $n$ - концентрация ионов внутри и вне клетки $\left(\sim 140\right.$ моль/м $\left.{ }^{3}\right)$. Полагая деформацию $\varepsilon=x / l(l-$ размер клетки) и используя (2), уравнение скорости деформации:

$$
\dot{\varepsilon}=\left[a\left(\frac{\Delta n}{n}+\frac{\Delta T}{T}\right)-\varepsilon\right] \tau_{b}^{-1},
$$

где $\tau_{в}-$ характерное время диффузии воды через мембрану, $a=\frac{n R T d^{2}}{h l E}$. Изменение темпера-

туры $\Delta T$ связано с различием коэффициентов оптического поглощения по разные стороны мембраны и описывается уравнением:

$$
\Delta \dot{T}=b I(t)-\frac{\Delta T}{\tau_{T}},
$$

где $\mathrm{b}=\alpha / c \rho, \alpha$ - разница коэффициентов поглощения в области $d$ и вне ее, $c$ и $\rho$ - теплоемкость и плотность среды, $I(t)$ - плотность потока излучения, $\tau_{T}-$ время температурной релаксации $\tau_{T}=d^{2} / \kappa\left(\kappa \sim 1,5 \cdot 10^{-7} \mathrm{~m}^{2} / \mathrm{c}\right.$ - температуропроводность). Диффузия ионов натрия и калия из внешних областей (не через мембрану), а также смещение мембраны, сопровождающееся диффузией через нее воды, приводит в условиях неравномерного нагрева к изменению разности концентраций по обе стороны мембраны:

$$
\Delta n=-2 n \varepsilon-\frac{\Delta n}{\tau_{D}}
$$

где $\tau_{D}=d^{2} / D_{N a, K}-$ характерное время диффузии ионов $\mathrm{Na}^{+}, \mathrm{K}^{+}$в среде. В случае непрерывного воздействия лазерного излучения при предположении $\tau_{D}>>\tau_{T}\left(\tau_{D} / \tau_{T} \sim 10^{2}\right) \tau_{D}>>\tau_{T}$ на больших временах решение системы (3-5) дает $\varepsilon \cong \frac{a b I \tau_{T}}{T}$. Это стационарная деформация при непрерывном облучении.

Для нахождения зависимости $\varepsilon$ от частоты посылки лазерных импульсов необходимо положить $I(t)=I_{0}(1-\sin (\omega t))$. Тогда частота с наибольшей амплитудой колебаний, находится из условия $\partial \varepsilon / \partial \omega=0$.

$$
\omega_{\max } \cong \frac{1}{\left(\tau_{D} \tau_{B} \tau_{T}\right)^{1 / 2}\left(\tau_{B}^{-2}+\tau_{T}^{-2}\right)^{1 / 4}}
$$

Из (6) с учетом зависимостей характерных времен от $d$ получим соотношение (1). Если оценивать эффективность лазерной терапии по амплитуде деформаций, то она оказывается наибольшей в случае использования импульсного воздействия с частотой, вычисляемой из морфологических особенностей биоткани. При воспалительных процессах затруднено движение жидких компонент в органах на клеточном уровне. «Мягкое» же нерезонансное действие импульсного излучения стимулирует микроциркуляторные процессы.

\section{Результаты экспериментальных исследований}

Исследования влияния ИК-облучения с длиной волны 0,89 мкм проводили на монослойных культурах клеток эмбриональной почки человека, трансформированные ДНК аденовируса типа 5 (Ad5) (НЕК-293). Эукариотические клетки НЕК293 культивировали в инкубаторах, поддерживающих температуру $37{ }^{\circ} \mathrm{C}, 100 \%$ влажность и концентрацию $\mathrm{CO}_{2} 5 \%$, в ростовой среде DMEM (Dulbecco's modified Eagle's Medium), без глутамина с содержанием глюкозы не менее 4,5 г/л. При процедуре пересева происходило снятие 
клеток с использованием трипсина $0,25 \%$ и версена $0,02 \%(1: 1)$, кратность рассева $1: 8$, оптимальная плотность 3,0-5,0 $\cdot 10^{4}$ клет./см². Клетки прикреплялись к субстрату в течение нескольких дней $[14$, 15]. Монослойное культивирование клеточных линий НЕК-293 осуществлялось в специальных одноразовых флаконах Т-25. Культивированные клетки после прикрепления к поверхности субстрата находились в непосредственном контакте, обеспечивая нормальный рост и размножение в питательной среде.

Из соотношения (1) была рассчитана частота импульсного ИК-воздействия на клеточную культуру - 272 Гц. Скважность зависит от необходимой длительности импульсов, которая определяется из следующего. Давление на мембрану $\Delta \mathrm{p}$ при перепадах температуры и концентраций ионов возникает вследствие различной проницаемости мембран для воды (характерное время диффузии через мембрану $\tau_{s} \sim 10^{-4}$ с) и для ионов $\left(\tau_{i} \sim 10^{0}-10^{2} \mathrm{c}\right)$ [7]. Поэтому деформации помимо частоты зависят от длительности импульсов. При коротких импульсах $\tau_{L}$, когда $\tau_{s}>\tau_{L}$, время температурной релаксации можно оценивать, как $\tau_{T}=\mathrm{d}^{2} / \kappa$. Такая оценка справедлива для размеров $d>4$ мкм, когда время температурной релаксации превышает время деформации мембраны $\tau_{6}$. Для меньших размеров, для HЕК-293 $d \leq 4$ мкм, температурное поле выравнивается быстрее, чем происходит деформация мембран. Из этого следует, что длительность импульсов ИК-облучения должна быть порядка характерного времени проникновения молекул воды сквозь мембрану, то есть 100 мкс.

Поскольку длительность импульсов лазерных терапевтических аппаратов на GaAs-лазерных диодах составляет от 100 до 300 нс, облучение проводили с помощью GaAs светодиодов, запитываемых от генератора с регулируемым рабочим циклом.
Это позволило провести сравнение двух режимов облучения, импульсного, с частотой 272 Гц и скважностью 36 \% и непрерывного. При импульсном облучении с мощностью в импульсе $5 \mathrm{MBT} / \mathrm{cm}^{2}$ сред-

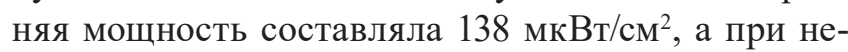
прерывном была выше -313 мкВт/см².

В результате исследования облученных клеточных структур с помощью оптической микроскопии было обнаружено, что влияние облучения приводит к увеличению контраста границ клеток, как показано на рис. 1. Такие изменения происходили только после импульсного облучения. Проявление контраста границ клеток на оптических изображениях следует связывать с увеличением толщины около или межклеточного заполненного жидкостью пространства. Это происходит за счет стимулирования импульсным излучением периодических микродеформаций клеточных мембран. В клеточных колониях это проявляется в увеличении видимой толщины приграничного с поверхностью клеток слоя. На изображении видно, что отдельные, изолированные или частично изолированные клетки даже могут приобретать правильную равноосную форму.

Всего было проведено по 3 серии 20 минутных облучений в импульсном и непрерывном режимах. Во всех опытах наблюдали отличия изображений клеточных структур после импульсного облучения. На рис. 2 показаны колонии эмбриональных клеток почки человека контрольной необлученной группы, культуры, облученной в импульсном режиме и культуры, облученной в непрерывном режиме, непосредственно после 3-го сеанса облучения. Видно, что изображения контрольной и облученной в непрерывном режиме культур сходны. Однако после импульсного облучения происходит увеличение количества клеток с повышенным контрастом границ. На общее количество клеток
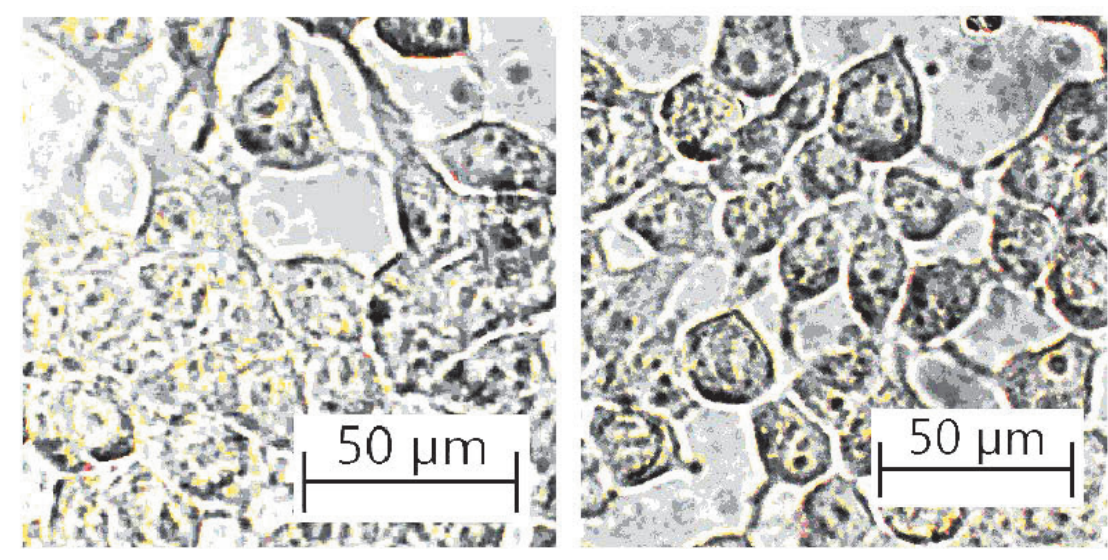

Рис. 1. Оптическое изображение клеточной культуры НЕК-293

исходной (слева) и после импульсного ИК облучения (справа) 


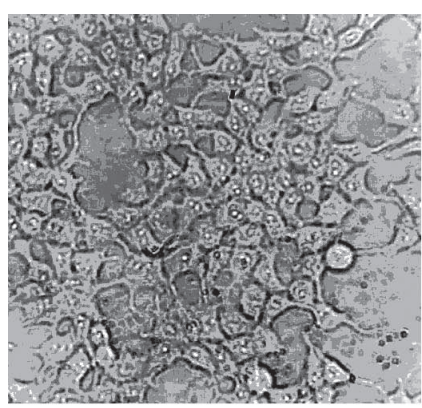

1

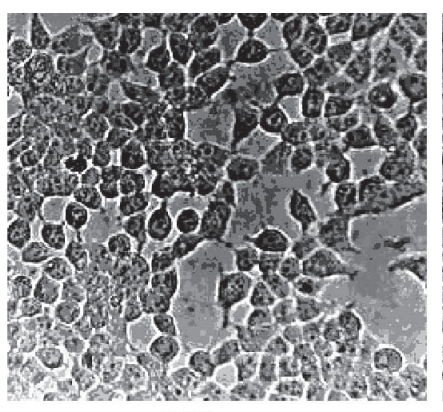

$2 \stackrel{100 \mu \mathrm{m}}{\longmapsto}$

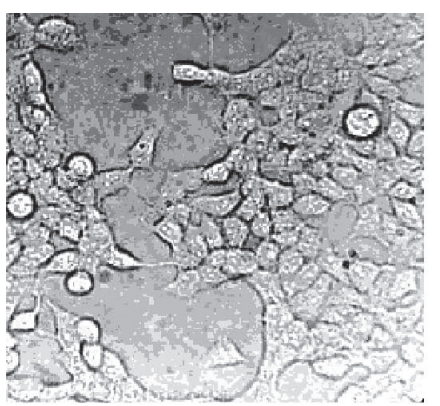

3

Рис. 2. Оптическое изображение клеточной культуры НЕК-293:

контрольная группа (1), после трех сеансов 20 минутного ИК-облучния, импульсного (2) и непрерывного (3)

ИК-облучение во всех опытах не оказывало никакого влияния.

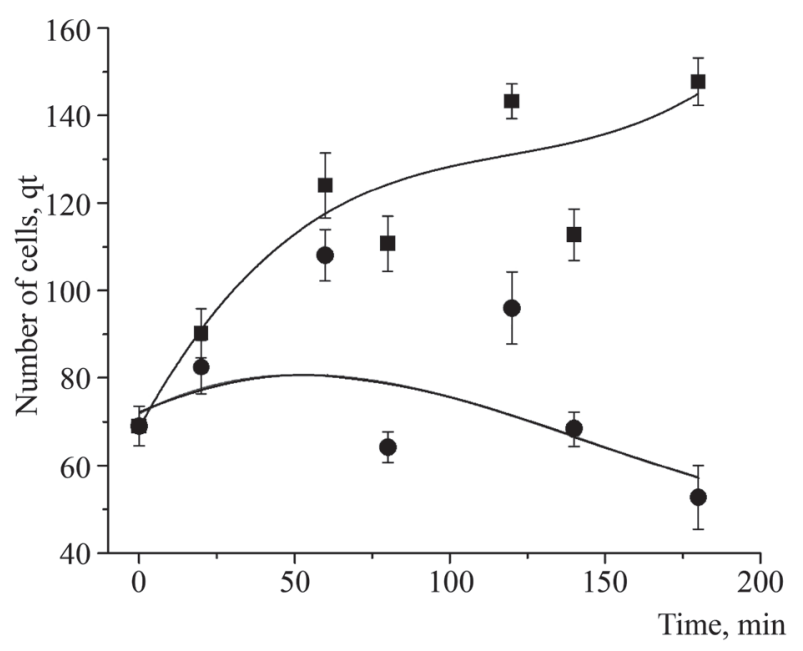

Рис. 3. График зависимости количества клеток НЕК-293 с контрастными границами от времени до и после 20 мин облучения в импульсном и непрерывном режимах

Можно проследить изменения количества с контрастными границами в разных группах клеточных культур. На рисунке 3 видно, что после 20 мин облучения в импульсном режиме происходит рост количества клеток с контрастными границами в течение, как минимум, 3 часов, а после непрерывного облучения их количество по сравнению с контрольной группой не изменилось. После импульсного воздействия превышение количества клеток с видимым контрастом границ относительно контроля составляет почти 200 \%. Оказалось, что структуры с контрастными границами существуют конечное время. После культивирования клеточных структур на 2 сут- ки в группах не обнаружено никаких различий. Все клетки первого поколения после импульсного и непрерывного облучения выглядели одинаково и показали одинаковый рост по всей поверхности флакона.

\section{Выводы}

Доказано влияние импульсного низкоинтенсивного ИК-облучения с длиной волны 0,89 мкм на культуру клеток эмбриональной почки человека НЕК-293, заключающееся в увеличении толщины около/межклеточного заполненного жидкостью пространства в результате стимулирования периодических деформаций клеточных мембран. Это происходит в соответствии с механизмом нерезонансного действия излучения в ближней ИКобласти на микроциркуляторные процессы в биотканях и проявляется в увеличении контраста границ клеток на оптических изображениях.

Авторы глубоко признательны сотрудникам и студентам отделения биотехнологий Обнинского института атомной энергетики за помощьв в подготовке и проведении экспериментов.

\section{Лumepamypa}

1. Скобелкин О.К. Лазеры в хирургии. - М.: Медицина, 1989. $256 \mathrm{c}$.

2. Шахно E.A. Физические основы применения лазеров в медицине: Учебное пособие. - СПб.: НИУ ИТМО, 2012. 129 с.

3. Холмогоров В.Е., Крыленков В.А., Османов М.А. Первичные фотопроцессы в крови и ее компонентах при действии оптического излучения // В кн.: Молекулярные механизмы биологического действия оптического излучения / Под ред. А.Б. Рубина. - М.: Наука, 1988. С. 164-177. 
4. Воронина О.Ю., Каплан М.А., Степанов В.А. Нерезонансный механизм биостимулирующего действия низкоинтенсивного лазерного излучения. / Препринт ФЭИ 2094. - 1990, 26 с.

5. Воронина О.Ю., Каплан М.А., Степанов В.А. Письма в ЖТФ. 1990. Т. 16. Вып. 6. С. 46-49.

6. Шейко Е.А., Златник Е.Ю., Закора Г.И. Сибирский онкологический журнал. 2009. 223 с.

7. Voronina O.Yu., Stepanov V.A. Blood microvessels circulatory system of intermal organs under conditions of laser therapy. / 1992 International Conference on advanced and laser technologies (ALT 92), Moscow, 8-11 Sept.,1992. Book of summaries. Part 4. P. 101-103.

8. Voronina O.Yu., Stepanov V.A. Laser radiation influence upon protein hydrosole and cell membrane states. / 1992 International Conference on advanced and laser technologies (ALT 92), Moscow, 8-11 Sept.,1992, Book of summaries, Part 5. P. 122-123.
9. Жуков В.В., Кожин А.А., Мрыхин В.В. Известия вузов. Северо-Кавказский регион. естественные науки. 2016. № 1. С. 54-60.

10. Никитин А.В., Орлова Е.В., Крючкова А.В., Малюков Д.А., Титова Л.А., Золотарева М.А. Лазерная медицина. 2008. Т. 12. Вып. 1. С. 26-30.

11. Плавский В.Ю., Барулин Н.В. Лазерная медицина. 2009. Т. 13. Вып. 1. С. 4-10.

12. Кару Т.Й., Календо Г.С., Лобко В.В. Изв. АН СССР. Сер. физическая. 1983. Т. 47. № 10. С. 2017-2022.

13. Karu T. Health Physics. 1989. V. 56. N. 5. P. 691-707.

14. Мамаева C.E. Атлас хромосом постоянных клеточных линий человека и животных. - М.: Научный Мир. 2002. 236 с.

15. Российская коллекция клеточных культур позвоночных (РККК П) / Сост. Полянская Г.Г., Сакута Г.А. (ИНЦ РАН), Еропкин М.Ю., Смирнова Т.Д. (НИИ гриппа РАМН) и др. -138 с. 